\title{
A Systematic Study for Smart Residential Thermostats: User Needs for the Input, Output, and Intelligence Level
}

\author{
Pei-Luen Patrick Rau *, Yun Gong, Han-Jing Huang and Jing Wen \\ Department of Industrial Engineering, Tsinghua University, Beijing 100084, China; \\ gong-y14@mails.tsinghua.edu.cn (Y.G.); huanghj15@mails.tsinghua.edu.cn (H.-J.H.); avenjing@163.com (J.W.) \\ * Correspondence: rpl@tsinghua.edu.cn; Tel.: +86-10-62776664
}

Academic Editor: Burcin Becerik-Gerber

Received: 15 January 2016; Accepted: 26 April 2016; Published: 29 April 2016

\begin{abstract}
The development of "smart" residential thermostats—both in terms of wider connectivity and higher intelligence-has revealed great opportunity for energy conservation, as well as providing comfort and convenience. This paper focuses on the interaction design of such a novel system, and analyzed user requirements for input, output, and level of intelligence systematically through both in-depth interviews and a survey.
\end{abstract}

Keywords: smart thermostat; user needs; user interface; automation

\section{Introduction}

With the rapid development of smart buildings worldwide, end user experience becomes increasingly important-it is more than technological sophistication. In the U.S., the energy for residential heating and cooling amounts to a high of $9 \%$ of the total primary energy use [1,2]. As an attempt to save energy, programmable thermostats have been promoted all over the world to automatically relax temperatures at night or during unoccupied periods according to the presets. Such programmable thermostats can theoretically reduce energy usage by $5 \%-15 \%$, but a recent study reported that users were shutting down their smart thermostats due to poor usability [3], as many users complain that they are too complicated to use and the effect is limited.

The development of advanced techniques, such as machine learning, speech recognition, and motion detection, reveal great opportunities for residential thermostats, but it is also a challenge to integrate these techniques with old user interfaces without producing negative experiences. Take the most popular smart thermostat as an example; Nest provides fascinating functions such as auto-schedule and auto-away, utilizing machine learning and occupancy detection technology to simplify control tasks. However, new usability problems emerge: people are losing a sense of control. The heating was sometimes turned on for no reason (probably because the user had turned it on the day before after a shower and this behavior was recognized and learned permanently). The temperature remains unrelaxed because the movement of pets were detected. As a result, users shut down automation [3,4]. The interaction design of smart thermostats has become a significant issue.

This study aims to provide a systematic user study on the requirements and expectations of residential smart thermostats. Three variables are discussed: input, output, and level of intelligence. The research questions include:

Input: Via what platform? With buttons, touch screen, speech, or gesture? Should it be set-based or satisfaction-based?

Output: What to display? How to display? Where to display?

Level of intelligence: How do users like automation in indoor environment controls? What type of automation is preferred? 
To answer these questions, interviews and a survey were conducted. The goal of the interviews was to collect the user habits and the expectations of residential thermostats and, in general, to explore the potential individual differences in the use of thermostats. Subsequently, the survey was conducted to answer more specific questions about user behavior with the thermostat, user preferences for input/output, and important elements of the user interface.

\section{Related Work}

\subsection{Smart Home}

The concept of smart home was first used by the American Association of House Builders in 1984. A Smart Home system is "a physical world that is richly and invisibly interwoven with sensors, actuators, displays and computational elements, embedded seamlessly in the everyday object of our lives, and connected through a continuous network," providing ways for controlling, interacting, and monitoring the house [5].

Since the 1990s, the ubiquitous home network became the new trend to integrate individual electronic control devices. Compared to a traditional home, the ubiquitous home network had the capacity of adjusting its function according to the status and needs of users, equipment, and environment. Meanwhile, the ubiquitous home network can hide the information of the system's mechanism, information exchange, and user network, which was irrelevant to the user experience. This hidden information technology provided opportunities for users to focus more on the operational task. Equally interesting, however, users may prefer to manually control the task they were familiar with. Rodden and Benford pointed out that the human-computer interaction in the smart home should be evolved from the existing interactive mode [6].

By the beginning of the 21st century, the development of smart home emphasized the concept of "Internet of Things". The "Internet of Things" opened up a whole range of possibilities for exchanging information between people, appliances, systems, and networks. With networks, users can control the household appliances through the control panel, webpage [7], the social platform [8], phone [9], and even the table [10] or the wall [11]. Some research claimed that the main challenge was to develop appropriate standards and protocols for interconnectivity between multiple networks, both within and outside the home [12].

\subsection{Classification of Smart Home Devices}

To better understand the opportunities and challenges of a smart system in a home, this study reviews several smart home control devices. This review mainly focuses on three issues: the interaction platform, interaction modality, and automation.

There are three basic platforms to develop interactive technologies for domestic settings: interactive appliances, augmented furniture, and information applications [6]. Interactive appliances add interactive capacities to the existing household, which offers new forms of interaction. For example, the refrigerator can be directly controlled by voice. Augmented furniture is the furniture equipped with interactive capacities. Examples of these include the DiamondTouch interactive table [13]; the display can be activated to control household devices. An information application integrates the existing information technology equipment. For example, people can use a telephone, pad, or television to interact with household devices.

The interaction modality mainly includes touchscreen interaction, voice interaction and gesture interaction. Taking the thermostat as an example, the touchscreen interaction is common in the mobile APPS and wall-mounted thermostats equipped with a touchscreen. Touchscreen interaction provides a high level of precision [9]. Voice interaction often acts as an assistive function for the touchscreen interaction [14,15]. Voice interaction is effective in situations where a user's hands and eyes are busy doing other tasks. Voice interaction usually uses some keywords as user commands. However, lack of accuracy is another problem resulting from the difference of expression habit and recognition accuracy. 
Gesture interaction uses a wireless sensor package with multiple accelerometers to capture the spatial trajectory of the gesture. Gesture interaction also has obstacle of low accuracy $[10,16]$. Users still need some practice to control the thermostat. People also claim that the simple gesture interaction is not as natural as they want. Moreover, the gesture interaction requires large data processing [17], transparency to user [5], and security issues concerning the increasing number of sensors around users [18].

Automation control includes human sensor automation, environment-based automation, and history-based automation. Human sensor automation applies infrared detectors to track the position, number, and temperature of the sources of heat and directly control the temperature to the user's need. Environment-based automation perceives the difference between the indoor and outdoor temperature and automatically adjusts the indoor temperature. History-based automation adjusts the temperature according to users' usage history. For example, Nest would learn people's usage in the first week, and later adjust the temperature without the users' participation based on a weekly schedule. However, machine learning may require more sophistication to be useful, rather than just repeat what users did. It should distinguish which adjustment is a regular input and what is an exceptional case $[3,19]$.

\subsection{Usability of Smart Home Devices}

Some usability research indicated some facts about user requirements and preferences in the use of smart home devices.

For the interaction platform, users prefer the mobile phone for instant control and the computer for pattern control [20]. For the interaction modality, people have different needs in different situations. For voice interaction, most people accept voice control when the task is easy and error-prone, but they also fear that the system will misunderstand their words. The negative attitude derives from the experiences with the cumbersome voice assistant in mobile phones. For the movement modality, people claim the simple gesture interaction is not as natural as they want. People prefer the GUI system because they believe visible icons and buttons make the task easier.

In the acceptance of automation control, people usually show great interest in, and need for, automation in surveys and interviews [21]; however, the interest in automation is lower in field studies [20,22]. For example, in a survey of 200 people, people showed an interest in using multimodal commands to control lights and the thermostat remotely, and open and close windows and shutters automatically. However, a three-year field study showed participants had considerable resistance towards the increase of proactive information technology in homes [22] . Another six-month study also showed that participants did not get used to the home's ability to "live a life of its own" [20].

Some researchers noted that trust was the important factor affecting people's acceptance of automation. When people do not absolutely trust automation, it can be semi-automated with some human intervention. There are two methods: one is that people preset an automation mechanism [20], the other is that automation cannot work without user permission [23]. Tiiu Koskela found that participants still believed that technology cannot completely understand complicated environmental factors. This can be another factor influencing acceptance of the smart thermostat. Additionally, people wanted to take control and observed the effect of each operation [20]. A recent study showed that automatic environmental control should not always be the same, but adaptively designed in accordance with specific comfort-energy trade-off situations, considering different control scenarios, personal requirements, and cultures [24]. Trust should be established on users' understandings of the automation mechanisms. For example, some research showed that the Auto-Away feature of Nest was unpopular. Auto-Away is a feature that detects whether people are at home and automatically goes into away mode when no one is detected. The lack of a priori knowledge about how "Auto-away" works may make users feel less in control. To adapt to the new system, some users even changed it back to manual mode. Due to the inconvenience in controlling the system and the limitations of the technology, it turned out to not be necessarily energy-saving [3]. 
Some researchers pointed out that the following system characteristics may potentially improve the trust level of users to automation [23]: (1) automation technologies should be robust, fail-safe, and non-intrusive; (2) the level of automation should be carefully chosen. The complex work can be done by the system, but users should have the opportunity to make the most important decisions; and (3) the design should be predictable, transparent, and with feedback.

\section{Study 1: Exploring User Needs through Interviews}

The target test users stem from different backgrounds and are supposed to offer insight from different perspectives on the usage and expectation of thermostat user interface. Among these, 14 Chinese participants (eight males) aged from 25 to 71 years old were recruited in the interviews, with their occupations including a student, teacher, programmer, retired doctor, and engineer. Their residence statuses also varied from a single apartment or shared room to living with family members. All interviews were conducted in the lab except for one elderly woman who failed to come; her interview was conducted at the participant's home. Two staff members joined the interview sessions, one was responsible for hosting each interview and the other was in charge of audio recording. The interviews lasted for $1 \mathrm{~h}$ on average.

Interview questions (Table 1) were generated in three categories: demographic information; general questions about environmental comfort; and specific questions concerning input, output, and intelligence.

Table 1. Interview questions.

\begin{tabular}{|c|c|}
\hline Category & Question \\
\hline Demographic information & $\begin{array}{l}\text { - Age, living status, thermostat ownership, smart phone ownership, web } \\
\text { access, occupation }\end{array}$ \\
\hline General questions & $\begin{array}{l}\text { - How do you define a comfortable environment? What is your preference } \\
\text { - } \quad \text { What is your habit when using a thermostat (when and why do you } \\
\text { regulate, frequently used functionality, sleep settings)? } \\
\text { - Describe the ideal controller. }\end{array}$ \\
\hline Specific questions & $\begin{array}{l}\text { - Input: What are the conveniences and inconveniences of current } \\
\text { controller? (Not limited to thermostat) } \\
\text { - Output: What information do you expect the thermostat to display? } \\
\text { Intelligence: What do you want the thermostat to do for } \\
\text { you automatically? }\end{array}$ \\
\hline
\end{tabular}

The interview data were coded and analyzed using a structured process: open coding, axial coding, and selective coding. A detailed record of each participant's answer can be found in the Table A1.

\subsection{Results}

\subsubsection{Input: More Accessible Access}

Almost all participants (10/12) liked the idea of setting the temperature when they were away from home. One person mentioned the scenario of controlling the automobile air conditioner. "When I was buying my car, I wanted to buy the car with a remote controller to turn on the AC before getting into the car."(P7) Some participants still believed it was more convenient to use a remote control at home. "I am using an app to control my TV, it is very convenient and I don't have to look for the remote control ever since."(P1) They enjoyed adjusting settings at night without getting out of 
bed. "Sometimes I do feel hot at night, but I am just too lazy to look for the controller." (P6) They actually wanted an instant controller that would enable them to make adjustments at any place, at any time. This finding indicated a new interaction paradigm with multiple access methods. Almost all participants appreciated the possibility of integrating controllers into one. They had problems with finding controllers all of the time. "I have three controllers to control the ACs in different rooms and it always occurred that I couldn't find them. I wish I could control all ACs with one controller."(P3).

\subsubsection{Automation: Balance the Sense of Control}

It was interesting to note that the key word "automation" had the highest occurrence frequency in the description of ideal appliances. They expressed that the full-automatic washing machine and refrigerator were easy to use. They can simply turn the machine on with one button operation. "I like the control of my soy milk machine. I just need to press one button to start the process and then it is all the machine's business."(P5). Participants had different opinions of automation. Five participants preferred the full-automatic thermostat: "I hope the system can learn my control habits and ultimately replace me."(P8) "I want to have central AC at home and it would be so great if it could keep me comfortable all the time."(P3) Other participants preferred the adjustable automatic thermostat. "Now we have to turn on the AC manually, but I wish that AC could be automatically turned on when the temperature is beyond my comfort range."(P4) Participants also expressed their concern about system failure. "People's behavior is random, I am feared that the machine cannot learn well." Some of them were even afraid of new technology. "I don't want it to be too advanced. It scares me."(P9) Thus, some participants still wanted to gain a sense of control.

This finding reflected that people expected the automatic thermostat, but they still cannot fully trust the machine because of immature technology. Without appropriate feedback, higher level of automation may cause some fears. However, most of fears can be addressed by the semi-control. People can set a control rule to make the machine run as they hope. This is confirmed by other studies.

\subsubsection{Output: More Information about Results of Operation}

As temperature was the only data provided by current thermostats, users were concerned with other operational conditions of the AC such as whether it was running, when they needed to change the filter, time to the target temperature, and environmental parameters such as humidity, outdoor temperature, weather forecast, air quality, etc. Participants also cared about how much they spent on air conditioning. People liked to know about running history, and they appreciated recommendations and alerts on energy saving. "I want to know how much money I can save if I raise the temperature by $1{ }^{\circ} \mathrm{C} . "(\mathrm{P} 9)$ "The system should tell me how much I would pay if I turned the AC on for the whole night." (P7) In all, participants focused more on the direct effect of their operations, rather than the data itself. User needs for output still varied with individual differences: older and female users cared more about information about energy and utility; young and male users cared more about comfort-related information. Most participants were curious about information such as the condition of the environment they were living in, the running status of the thermostat system, difference in power costs under different settings and feasible solutions to save energy. Moreover, people stressed the importance of the more intuitive display of information.

\subsubsection{Function: Integrate More Machines into One}

Although the question was about the control of the thermostat, almost all people (10/12) naturally talked about the need of thermostat function. It was not surprising that users liked to have more functions integrated in one machine. The most desired functions were purifying and humidifying air, which motivated people to replace old thermostat. However, even if some participants owned machines to purify and humidify air, they still needed a machine with all functions integrated. "I have an air cleaner, an air humidifier but I still want an AC with all of these functions integrated in it". (P4) Integrated machine can significantly save space and reduce the tasks for user. 


\subsubsection{Older People: Fear of Change}

It should be noticed that older people usually have different needs. Most of them kept the traditional consumer behavior and lifestyle. In most cases, they preferred to use fans to save money. Their body functions degenerate gradually, they could not clearly distinguish buttons on remote controller. Moreover, older participants were afraid of changes to the user interface. Most of these fears can be addressed by a good design. For example, the system can provide a special mode for the elderly, which keeps the original interface, simplifies the function of remote control and makes the system more stable.

\section{Study 2: Exploring User Needs through a Survey}

In all, 87 participants aged from 19 to 52 years old (mean age $=27.01, \mathrm{SD}=7.93$; male: $54.02 \%$ ) took the survey. All participants were recruited through social networking applications. Their occupations included student, teacher, programmer, doctor, and so on. Their resident statuses also varied from single apartment or shared room or live with family members. Before the questionnaire, six representative thermostats (Table 1) were introduced to participants in great detail. The selection criteria for the thermostats included the following: (1) they cover most input and output modalities; (2) most of them (except Type 6) are existing thermostats that could be bought on the market; (3) type 6 is a representative prototype of thermal-sensation control. For example, when someone feels hot, he/she pushes the "hot" button, the thermostat would lower the inside temperature. This type of control may be more suitable for people who do not know the operating mechanism of thermostats, especially for old people and children. The study explores whether using thermal-sensation would be more natural way to control thermostat.

Three sections were involved in the survey, focusing on user behavior, preferences for input/output modalities (Table 2), and display of information, respectively.

Table 2. Descriptions of the thermostats.

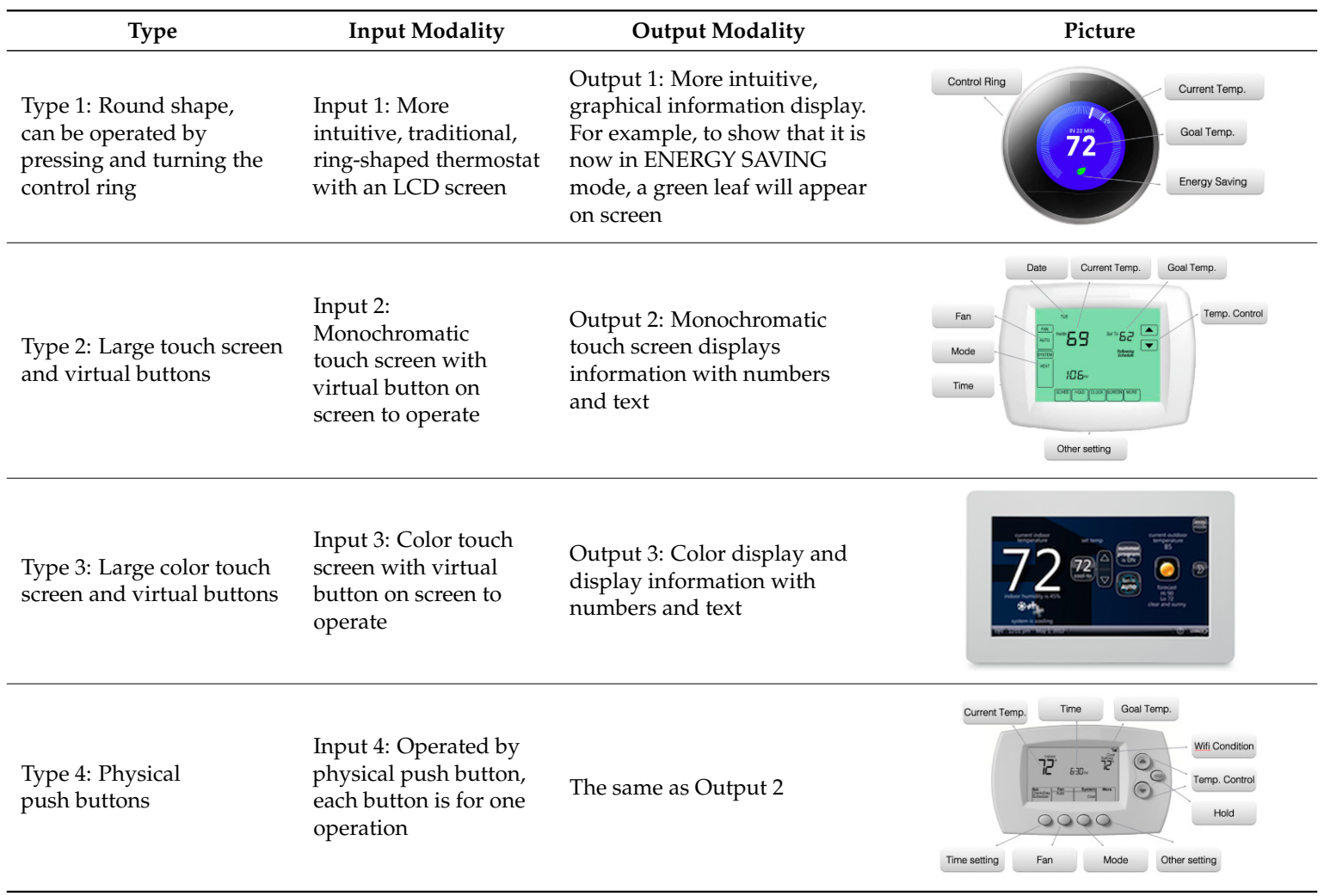


Table 2. Cont.

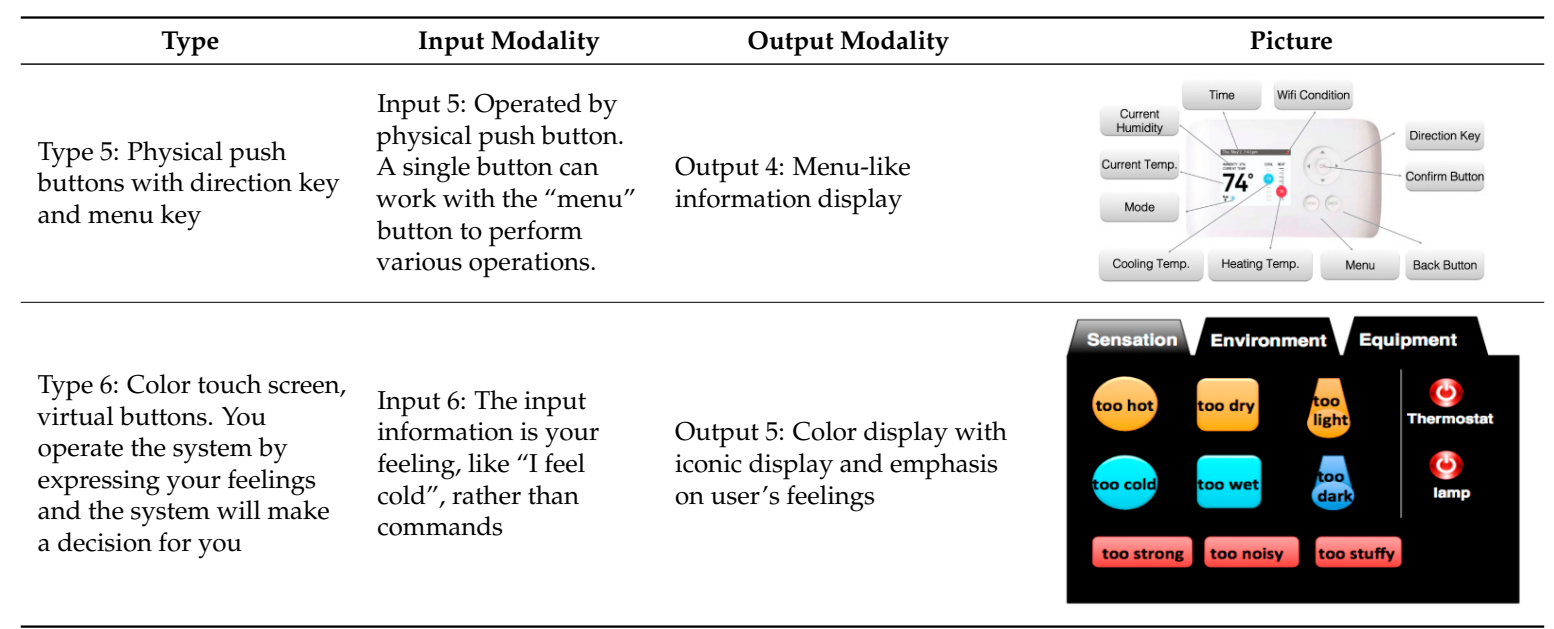

\subsection{Results of User Behavior}

Table 3 lists the descriptive data for user behavior. The questionnaire for user behavior mainly focuses on three aspects: user household activity (UB1, UB2, UB3), regular control (UB4, UB5), and mental model (UB6, UB7, UB8). The agreement to each statement was measured by a seven-point Likert scale ranging from 1-strongly disagree to 7-strongly agree. Mean and standard deviation of the ratings are given as follows.

Table 3. Descriptive data of user behavior.

\begin{tabular}{|c|c|c|c|}
\hline Notation & User Behavior & Mean & SD \\
\hline UB1 & I always carry my phone with me when I'm home. & 4.99 & 1.85 \\
\hline UB2 & When I'm home, I always stay in the same room for a long time. & 5.61 & 1.54 \\
\hline UB3 & I always disagree with my family about setting the proper temperature. & 3.29 & 1.68 \\
\hline UB4 & $\begin{array}{l}\text { During workdays, I control the temperature with regular adjustments } \\
\text { to my thermostat. }\end{array}$ & 4.95 & 2.07 \\
\hline UB5 & $\begin{array}{l}\text { During weekends, I control the temperature with regular adjustments } \\
\text { to my thermostat. }\end{array}$ & 5.23 & 1.68 \\
\hline UB6 & $\begin{array}{l}\text { In my opinion, a thermostat is just a switch to control cooling or heating. } \\
\text { To be comfortable, I need to repeatedly regulate the thermostat. }\end{array}$ & 3.83 & 1.98 \\
\hline UB7 & $\begin{array}{l}\text { In my opinion, to be comfortable, all I need to do is to set a proper } \\
\text { temperature for thermostat, and it will finish the remaining work } \\
\text { automatically to guarantee my comfort. }\end{array}$ & 5.36 & 1.64 \\
\hline UB8 & $\begin{array}{l}\text { In my opinion, setting temperature lower than needed can speed up } \\
\text { cooling. (For example, the current temperature is } 25^{\circ} \mathrm{C} \text {, and I want to } \\
\text { set it to } 23^{\circ} \mathrm{C} \text {. To speed up cooling, I would set it to } 18^{\circ} \mathrm{C} \text {.) }\end{array}$ & 4.92 & 1.97 \\
\hline
\end{tabular}

\subsubsection{Household Activity}

Figures 1-3 show the distribution of agreement to UB1, UB2, and UB3. Figures 1 and 2 show that a high proportion of users carry their phones and stay in the same room when they are at home. The agreement to UB3 did not show a significant modality, which indicates there may be individual differences in the occurrence of comfort disputes. 


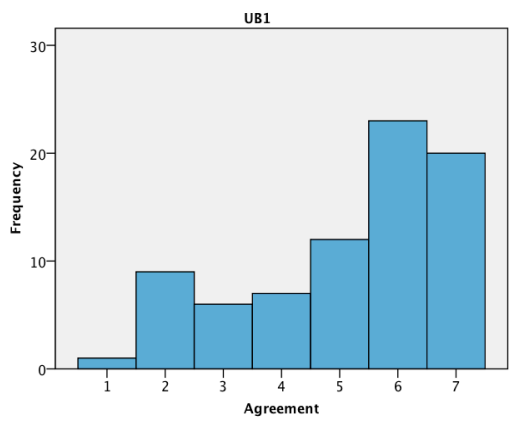

Figure 1. Agreement to User Behavior 1.

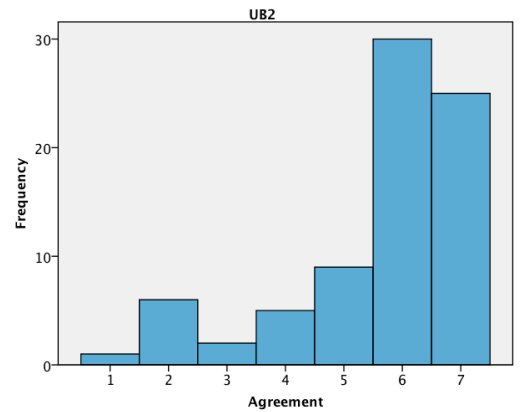

Figure 2. Agreement to User Behavior 1.

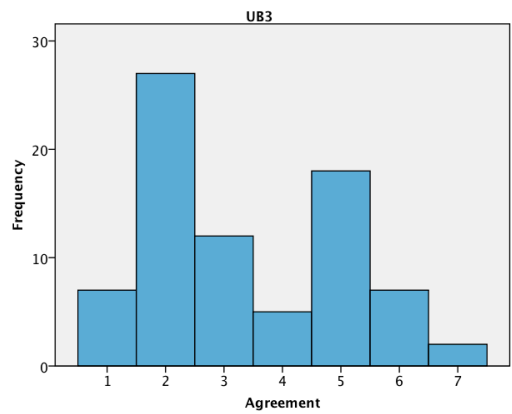

Figure 3. Agreement to User Behavior 3.

\subsubsection{Regular Control}

Figures 4 and 5 show the frequency distributions of agreement to UB4 and UB5, respectively. The results show that a high proportion of users regularly adjust their thermostat, both on weekdays and on weekends.

The $\mathrm{t}$-test result indicates that female users are doing more regular controls to the thermostat than male users do on workdays (female user: $5.79 \pm 1.28$, male user: $4.88 \pm 1.78, \mathrm{P}=0.017$ ). However, their regular controls of the thermostat on weekends are similar. 


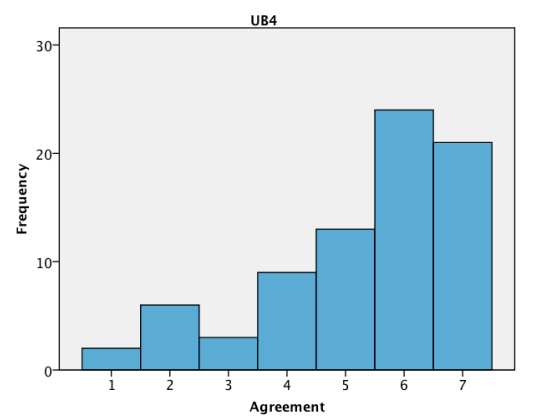

Figure 4. Agreement to User Behavior 1.

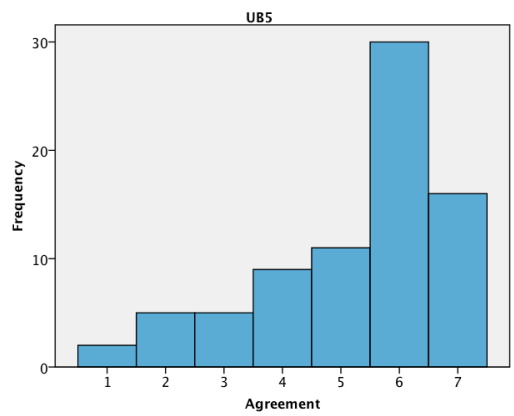

Figure 5. Agreement to User Behavior 1.

\subsubsection{Mental Model}

Figures 6-8 indicate that a high proportion of users believe that a thermostat will automatically guarantee their comfort after they set a proper temperature. A high proportion of people believe that setting the temperature lower than needed can speed up cooling.

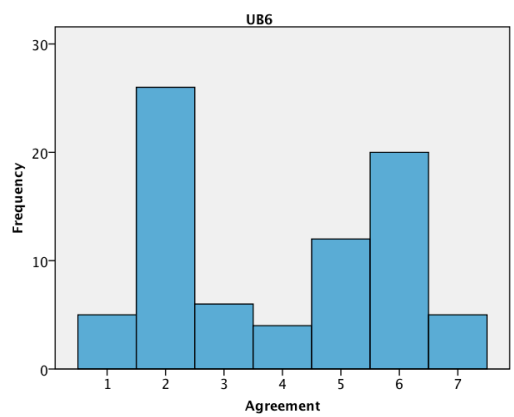

Figure 6. Agreement to User Behavior 1.

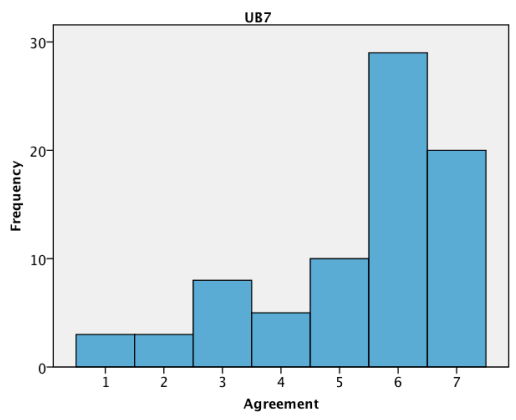

Figure 7. Agreement to User Behavior 1. 


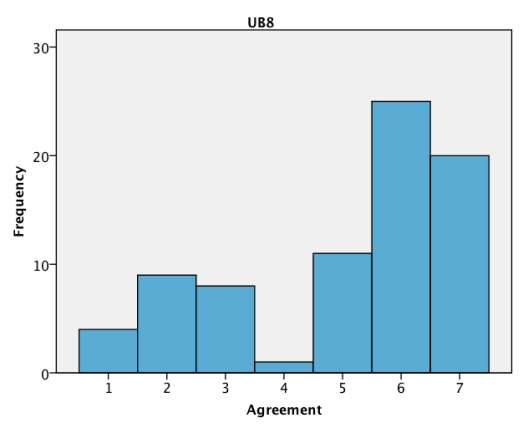

Figure 8. Agreement to User Behavior 3.

\subsection{Rank of Input Modalities}

Figure 9 ranks the preference for six typical input modalities in the survey (note that lower rank means higher preference). The ring-shaped thermostat with an LED screen ranked first, followed by the monochromatic touch screen and color touch screen. The satisfaction-based touch screen came in last, partially because it was just a prototype.

Results indicated that users preferred simple and accurate input with a color touch screen to physical push buttons. The preference for satisfaction-based input was polarized. It was the favorite input style for $14.9 \%$ participants (just lower than the ring-shaped thermostat with an LED screen and the large touch screen with color display), while it was also the least favorite input style for $51.7 \%$ participants. This suggests that satisfaction-based input could be a supplementary input method.

\section{Rank $^{1}$ of input modalities}

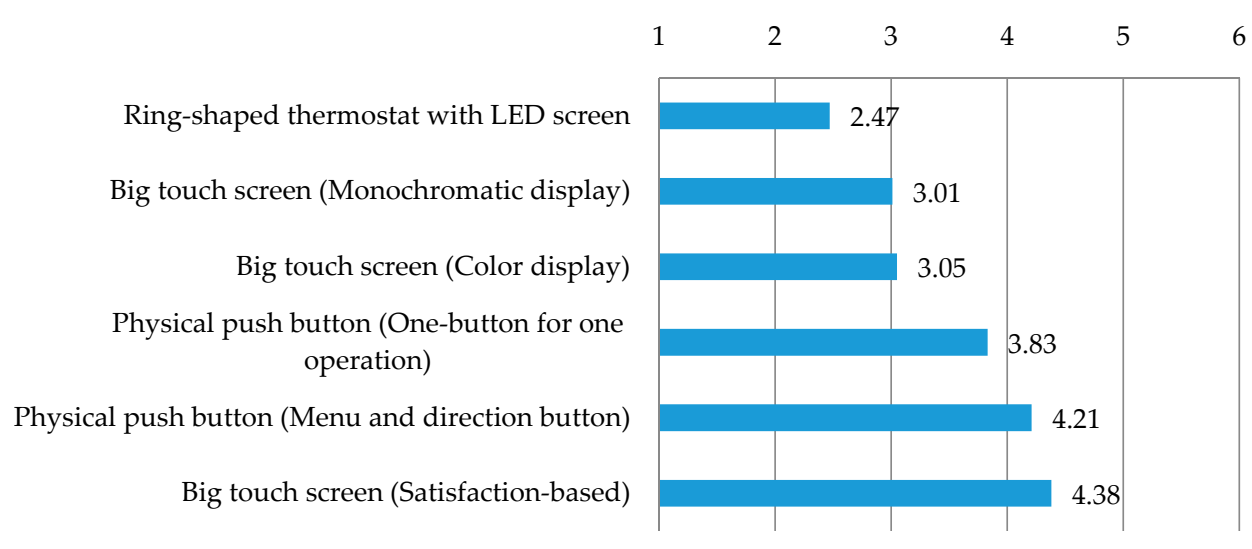

Figure 9. Rank of input modalities. ${ }^{1}$ Lower rank means higher preference.

\subsection{Rank of Output Modalities}

For the output modalities, Figure 10 calculates the mean rank for five typical output modalities (note that lower rank means higher preference). Graphical information display (mixed numbers and text) took first place, while output modalities based on numbers and text followed. Iconic display focusing on user's feeling came in last.

Results reflected user preferences for graphical and intuitive output with color display. Similar to the input modalities, the preference for satisfaction-based output was polarized. It was the favorite input style for $13.8 \%$ participants while it was also the least favorite output style for $44.8 \%$ of participants. This suggests that satisfaction-based input could be a supplementary output method. 


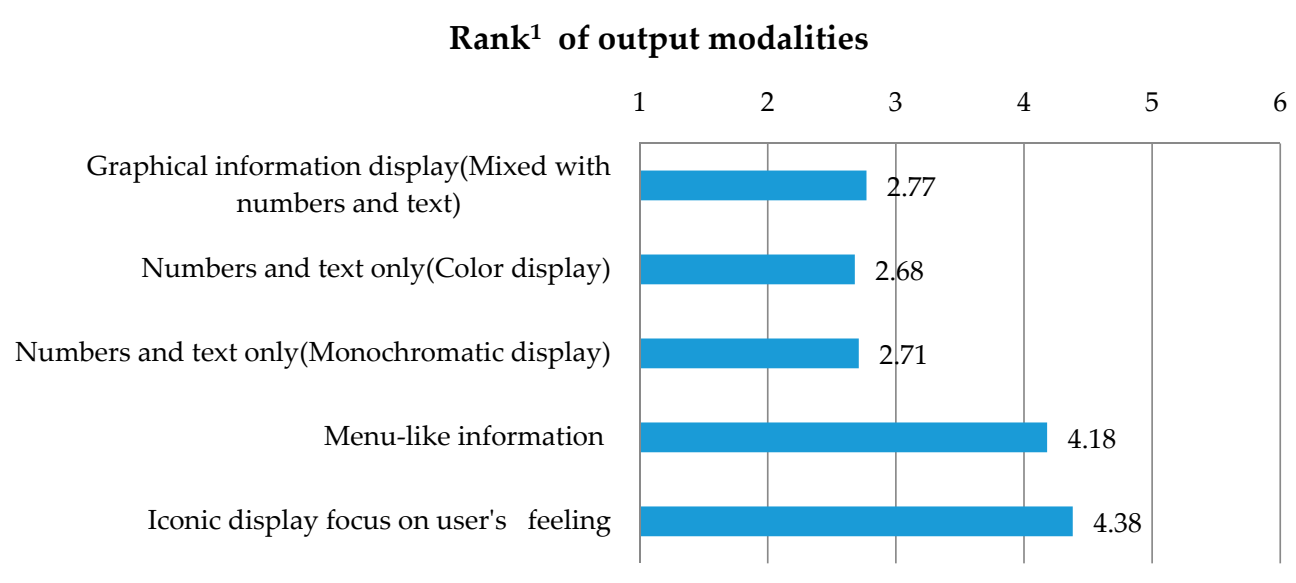

Figure 10. Rank of output modalities. ${ }^{1}$ Lower rank means higher preference.

\subsection{Importance Thermostat Designelements}

Table 4 shows the top 10 most important design elements out of the 18 design elements in the information display. The other eight design elements are local weather forecast, other related system information, help information, utility information, current energy price, audio touch confirmation, confirmation button, and one-button override.

The strongly required elements are mainly about output rather than input, and most of them are outputs of current status. Some of them have already been realized in existing products, while some still have not, such as a change filter alarm, an indication whether the thermostat is running, malfunction alarm, and current humidity. For input elements, copy scheme function and speed dial were regarded as important elements. For smart elements, energy consumption information and a malfunction alarm were regarded as important elements.

Table 4. Top 10 important design elements of thermostat out of 18.

\begin{tabular}{ccccc}
\hline Elements & Mean & SD & Category & Sub-Category \\
\hline Current temperature & 5.84 & 1.15 & Output & Current Status \\
Change filter alarm & 5.63 & 0.98 & Output & Current Status \\
Current mode, for example, sleep mode. & 5.40 & 1.06 & Output & Current Status \\
Low battery alarm & 5.40 & 1.06 & Output & Current Status \\
Indication whether the thermostat is now & 5.29 & 1.17 & Output & Current Status \\
actually working, instead of in idle mode. & 5.29 & 1.60 & Intelligence & Current Status \\
Malfunction alarm & 5.05 & 1.38 & Input & Input \\
Copy scheme function & 5.02 & 1.25 & Output & Current Status \\
Current humidity & & & &
\end{tabular}

From the above, the survey gives more specific results about users' needs and preferences. First, most users' behaviors are similar, and their user habits are influenced by past experiences; for example, most people believe that setting a lower temperature can speed up cooling. Second, user needs for input modalities and output modalities are different. For the input, people prefer simple and direct control of the thermostat. The ring-shaped thermostat with an LED screen and the touch screen are the most popular. For the output, people prefer clear and direct information displays including numbers and text. People want to know more information about the current environment, such as current temperature and humidity. They are also concerned about timely energy consumption information. Moreover, this survey explores people's attitudes towards a new interaction method based on satisfaction. The results show that people's preference on satisfaction-based input and output are polarized. Most people did not like satisfaction-based input and output. 


\section{Discussions and Conclusions}

This paper describes interviews and a survey to explore people's needs and preferences regarding thermostats, including control, display and intelligence.

For the thermostat user interface, people prefer a simpler, more intuitive, and convenient thermostat control. For convenience, one suggestion is to support control through multiple access methods. Now that most people have mobile phones with them all of the time, it is time to utilize such devices as new controllers. The controllers of household appliances should be more integrated with more appliances.

People need more integrative feedback about the current environment from the user interface. A smart thermostat should provide operational status, energy consumption information, and environmental status in greater detail. With a higher level of automation, more feedback should be offered to enhance users' trust in the thermostat and their feeling of involvement. In addition, one participant was interested in comparing his energy consumption performance to that of his friends or neighbors. This encourages the development of a sharing function that can not only make thermostat usage fun but also encourage energy-saving behavior.

For thermostat intelligence, different people have different levels of acceptance of smart thermostats. Female users and elderly users are afraid of changes in user interfaces and less interested in obtaining a smart thermostat. An improved traditional thermostat may better fit the needs of such users. Male users of approximately 30 years old were found to be the target users, as they are more willing to pay for technology. There can be different modes for different people. People are more concerned about energy-saving and health issues. Smart thermostats should create more functions to promote energy-saving behavior and users' health. This study also explores people's acceptance of satisfaction-based input and output, which is a new interaction method. The result showed that people's levels of acceptance are polarized. Most people dislike satisfaction-based input and output. This finding indicates that the design of the new interaction paradigm should also consider the users' different levels of acceptance and the reasons behind them.

This study also has theoretical implications for smart appliance design. Previously, little work has discussed people's needs and expectations of new smart appliances at home. The current study found that current technology can realize most customer needs. Researchers and designers should focus on the user needs for new products.

Finally, it is important to note that there are a lot of unsolved problems on hardware and technology in the real smart thermostats. In this study, limited consideration has been given to how to improve technology systems in thermostat. Another weakness of this study is that the research only conducted interview and survey to explore user needs about smart thermostat. The results may be different from user experience in real in situ conditions. More experiments should be done to verify the results. Moreover, this study makes incremental contribution by offering some guidelines to the design of thermostat, but this study does not propose a new subversive design.

This study hopes to raise awareness that designers should take full consideration of user needs and try to balance users' desire for innovative technology and the desire for a simple domestic lifestyle. In future work, this study plans to apply "in situ" methods to explore users need. This study can conduct some diary studies. This study also wants to learn more details about different people's preference for intelligent levels in different scenarios.

Acknowledgments: This research was supported by the United Technologies Research Center. We also wish to thank all of the participants for participating in the interview and openly discussing their opinions.

Author Contributions: P.-L.P.R., J.W., and Y.G. conceived and designed the experiments; Y.G., J.W., H.-J.H. performed the experiments; Y.G., H.-J.H. and J.W. analyzed the data; Y.G. and H.-J.H. wrote the paper.

Conflicts of Interest: The authors declare no conflict of interest. 


\section{Appendix}

Table A1. A brief record of interview results.

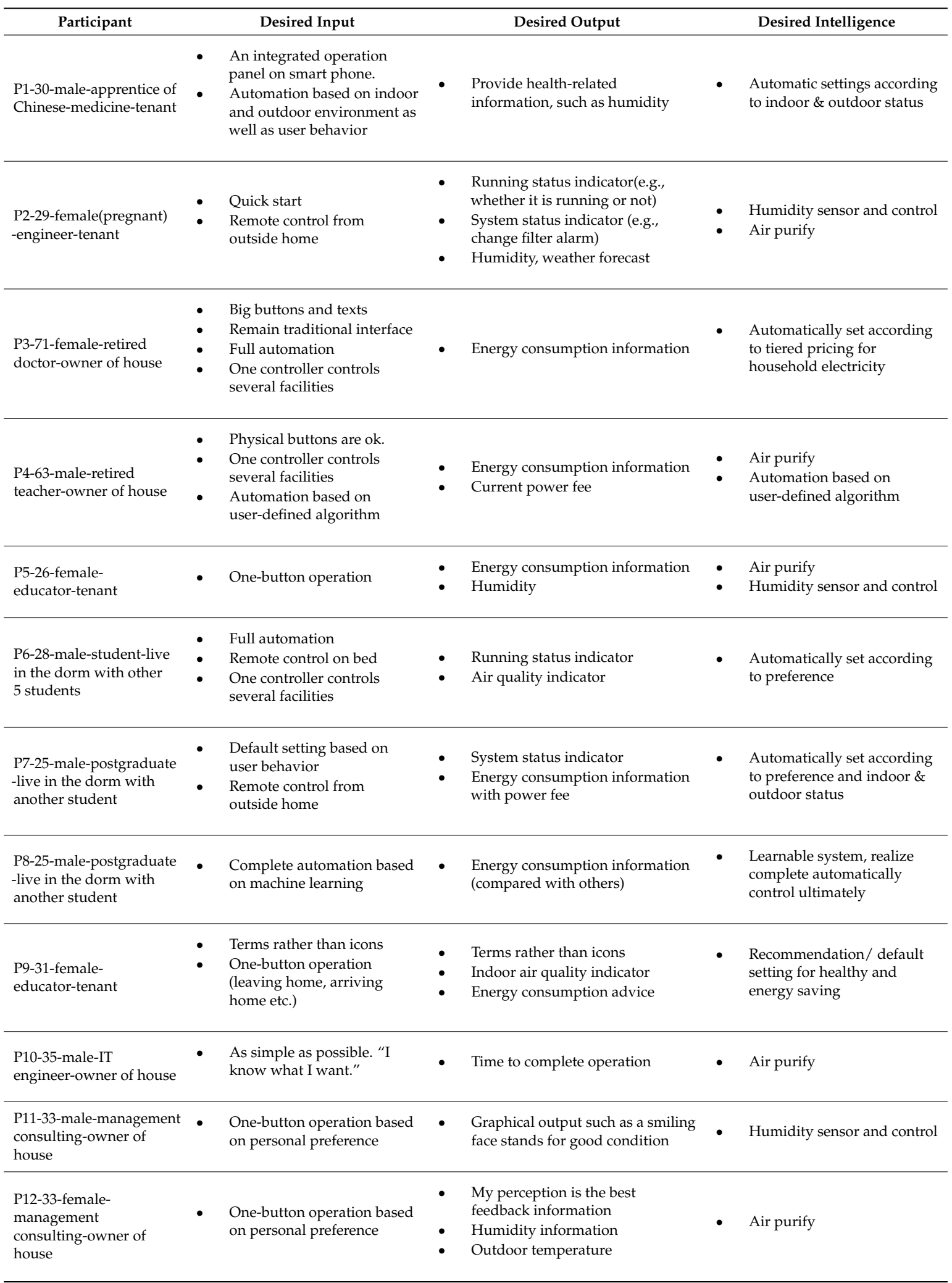


Table A1. Cont.

\begin{tabular}{|c|c|c|c|}
\hline Participant & Desired Input & Desired Output & Desired Intelligence \\
\hline $\begin{array}{l}\text { P13-28-female- } \\
\text { researcher-owener of } \\
\text { house }\end{array}$ & $\begin{array}{l}\text { - } \quad \text { Simple, one-button operation } \\
\text { Default settings such as } \\
\text { sleeping mode }\end{array}$ & $\begin{array}{ll}\text { - } & \text { Clear, close } \\
\text { - } & \text { Feedback of time to get my } \\
\text { set-point } \\
\text { - } & \text { Information of system status }\end{array}$ & $\begin{array}{l}\text { Detect the users' skin temp. } \\
\text { and regulate automatically } \\
\text { for special users such as } \\
\text { pregnant woman }\end{array}$ \\
\hline $\begin{array}{l}\text { P14-29-male-management } \\
\text { consulting-owner of } \\
\text { house }\end{array}$ & $\begin{array}{ll}\text { - } & \text { Simple, intuitive } \\
\text { - } & \text { Need remote access }\end{array}$ & $\begin{array}{ll}\text { - } & \text { Clear, simplest } \\
\text { - } & \text { Humidity sensor and report } \\
\text { Information of running time and } \\
\text { energy usage }\end{array}$ & - $\quad$ Simple and direct controlling \\
\hline
\end{tabular}

\section{References}

1. Residential Energy End-Use Splits By Fuel Type (Quadrillion Btu). Table 2.1.5. U.S. Department of Energy (DOE). Available online: http://buildingsdatabook.eren.doe.gov/ChapterIntro2.aspx?2\#1 (accessed on 6 April 2011).

2. Table 1.1 Primary Energy Overview, 1949-2009. Energy Information Administration (EIA). Available online: http:/ / www.eia.doe.gov/totalenergy/data/annual/txt/ptb0101.html (accessed on 25 May 2011).

3. Yang, R.; Newman, M.W. Living with an intelligent thermostat: Advanced control for heating and cooling systems. In Proceedings of the 2012 ACM Conference on Ubiquitous Computing, Pittsburgh, PA, USA, 5-8 September 2012.

4. Peffer, T.; Perry, D.; Pritoni, M.; Aragon, C.; Meier, A. Facilitating energy savings with programmable thermostats: Evaluation and guidelines for the thermostat user interface. Ergonomics 2013, 56, 463-479. [CrossRef] [PubMed]

5. Weiser, M. The computer for the 21st century. Sci. Am. 1991, 265, 94-104. [CrossRef]

6. Rodden, T.; Benford, S. The evolution of buildings and implications for the design of ubiquitous domestic environments. In Proceedings of the SIGCHI Conference on Human Factors in Computing Systems, Montreal, QC, Canada, 22-27 April 2006.

7. LaMarche, J.; Cheney, K.; Christian, S.; Roth, K. Home Energy Management Products E Trends; Fraunhofer Center for Sustainable Energy Systems: Boston, MA, USA, 2011.

8. Arachchilage, N.A.G.; Lauria, S.; Love, S. Twitter controls the household heating system. Int. J. Sustain. Energy 2013, 2, 101-104.

9. Zhong, Y.; Suo, Y.; Xu, W.; Yu, C.; Guo, X.; Zhao, Y.; Shi, Y. Smart home on smart phone. In Proceedings of the 13th International Conference on Ubiquitous Computing, Beijing, China, 17-21 September 2011.

10. Heidrich, F.; Golod, I.; Russell, P.; Ziefle, M. Device-free interaction in smart domestic environments. In Proceedings of the 4th Augmented Human International Conference, Stuttgart, Germany, 7-8 March 2013.

11. Kim, H.-J.; Jeong, K.-H.; Kim, S.-K.; Han, T.-D. Ambient wall: Smart wall display interface which can be controlled by simple gesture for smart home. In SIGGRAPH Asia 2011 Sketches; ACM: New York, NY, USA, $2011 ;$ p. 1.

12. Barlow, J.; Venables, T. Smart home, dumb suppliers? The future of smart homes markets. In Inside the Smart Home; Springer: London, UK, 2003; pp. 247-262.

13. Dietz, P.; Leigh, D. Diamondtouch: A multi-user touch technology. In Proceedings of the 14th Annual ACM Symposium on User Interface Software and Technology, Orlando, FL, USA, 11-14 November 2001.

14. Portet, F.; Vacher, M.; Golanski, C.; Roux, C.; Meillon, B. Design and evaluation of a smart home voice interface for the elderly: Acceptability and objection aspects. Pers. Ubiquitous Comput. 2013, 17, 127-144. [CrossRef]

15. Vacher, M.; Istrate, D.; Portet, F.; Joubert, T.; Chevalier, T.; Smidtas, S.; Meillon, B.; Lecouteux, B.; Sehili, M.; Chahuara, P. The sweet-home project: Audio technology in smart homes to improve well-being and reliance. In Proceedings of the 33rd Annual International Conference of the IEEE Engineering in Medicine and Biology Society (EMBC 2011), Boston, MA, USA, 30 August-3 September 2011. 
16. Rahman, A.; Hossain, M.A.; Parra, J.; El Saddik, A. Motion-path based gesture interaction with smart home services. In Proceedings of the 17th ACM International Conference on Multimedia, Beijing, China, 19-24 October 2009.

17. Wachs, J.P.; Kölsch, M.; Stern, H.; Edan, Y. Vision-based hand-gesture applications. Commun. ACM 2011, 54, 60-71. [CrossRef]

18. Abi-Char, P.E.; El-Hassan, B.; Mokhtari, M. Privacy and trust issues in context-aware pervasive computing: State-of-the-art and future directions. Trust Model. Manag. Digit. Environ. Soc. Concept Syst. Dev. 2010. [CrossRef]

19. Yang, R.; Newman, M.W. Learning from a learning thermostat: Lessons for intelligent systems for the home. In Proceedings of the 2013 ACM International Joint Conference on Pervasive and Ubiquitous Computing, Zurich, Switzerland, 8-12 September 2013.

20. Koskela, T.; Väänänen-Vainio-Mattila, K. Evolution towards smart home environments: Empirical evaluation of three user interfaces. Pers. Ubiquitous Comput. 2004, 8, 234-240. [CrossRef]

21. Callejas, Z.; López-Cózar, R. Designing smart home interfaces for the elderly. ACM SIGACCESS Access. Comput. 2009, 95, 10-16. [CrossRef]

22. Mäyrä, F.; Soronen, A.; Koskinen, I.; Kuusela, K.; Mikkonen, J.; Vanhala, J.; Zakrzewski, M. Probing a proactive home: Challenges in researching and designing everyday smart environments. Hum. Technol. Interdiscip. J. Hum. ICT Environ. 2006, 2, 158-186. [CrossRef]

23. Karjalainen, S. Should it be automatic or manual-The occupant's perspective on the design of domestic control systems. Energy Build. 2013, 65, 119-126. [CrossRef]

24. Rau, P.-L.P.; Gong, Y.; Dai, Y.-B.; Cheng, C. Promote energy conservation in automatic environment control: A comfort-energy trade-off perspective. In Proceedings of the 33rd Annual ACM Conference Extended Abstracts on Human Factors in Computing Systems, Seoul, Korea, 18-23 April 2015.

(C) 2016 by the authors; licensee MDPI, Basel, Switzerland. This article is an open access article distributed under the terms and conditions of the Creative Commons Attribution (CC-BY) license (http:/ / creativecommons.org/licenses/by/4.0/). 